\title{
A participação das comunidades tradicionais de terreiro no campo da saúde: as pesquisas em psicologia social
}

\author{
Participation by terreiro traditional communities in the health field: \\ research in social psychology
}

\section{La participación de las comunidades tradicionales de terreiro en el campo de la salud: las investigaciones en psicología social}

\author{
Sônia Regina Correa Lages ${ }^{a} \mathbb{D}^{-}$; Ariane Macthelly da Silva ${ }^{b} \mathbb{D}^{\mathbb{D}}$; Matheus Fernando Félix Ribeiro
}

\footnotetext{
${ }^{a}$ Professora de graduação e pós-graduação no Departamento de Psicologia da Universidade Federal de Minas Gerais, Belo Horizonte, MG, Brasil - Email: soniarclages@gmail.com

b Estudante de Psicologia na UFMG - Universidade Federal de Minas, Belo Horizonte, MG, Brasil - Email: arianemacsilva@gmail.com

${ }^{\mathrm{c}}$ Psicólogo, Especialista em Ciência da Religião pela PUC- SP. Mestre em Psicologia pela USP. Universidade de São Paulo, São Paulo, SP, Brasil - Email: matheusfelix.psi@gmail.com
}

Resumo: Esse artigo apresenta uma revisão bibliográfica sobre a saúde da população negra e a participação da religiosidade afro-brasileira, no campo da Psicologia Social. Ele integra uma pesquisa de cunho mais amplo que pretende colaborar com as propostas da Política Nacional para a Saúde da População Negra, que reconhece as comunidades tradicionais de terreiro como sendo promotoras da saúde. Considera-se aqui o papel da Psicologia Social, em sua vertente crítica, para com o combate ao racismo no Brasil, e para com as propostas de transformação social. A busca pela produção limitou-se às Revistas de Psicologia (em interface com o social), indexadas na Rede Scielo e na LILACS - Biblioteca Virtual em Saúde (Bireme). Foram encontrados apenas dois artigos, o que aponta para uma fragilidade das pesquisas neste campo, o que solicita à Psicologia Social uma reflexão sobre tal resultado, uma vez que restringe sua participação nos movimentos e lutas pela equidade étnico-raciais no Brasil.

Palavras-chave: Psicologia social. Equidade em saúde. Religiões afro-brasileiras.

\begin{abstract}
This article presents a literature review on health of black population and participation of african-Brazilian religion in the field of Social Psychology. It integrates a research of broader nature that aims to collaborate with proposals of the National Policy for Black Population Health, which recognizes traditional "terreiro" communities as health promoters. The role of social psychology is here considered, in its critical stance, towards the fight against racism in Brazil, and regarding proposals for overcoming health inequities. The search for scientific articles was limited to Psychology Journals (in interface with the social), indexed in SciELO and LILACS Networks - Virtual Health Library (Bireme). Only two articles were found, which points to a research weakness in this field, which invites Social Psychology to reflect about, since it restricts its participation in movements and struggles for ethnic and racial equity in Brazil.
\end{abstract}

Keywords: Social psychology. Health equity. Afro-brasilian religions. obra, forneça um link para a licença, e indicar se foram feitas alterações. 
Resumen: Este artículo presenta una revisión bibliográfica sobre la salud de la población negra y la participación de la religiosidad afro-brasileña en el campo de la Psicología Social. Que integra una investigación de cuño más amplia que pretende colaborar con las propuestas de la Política Nacional para la Salud de la Población Negra, que reconoce a las comunidades tradicionales de terreiro como promotores de la salud. Se considera aquí el papel de la Psicología Social, en su vertiente crítica, para con el combate al racismo en Brasil, y para con las propuestas de transformación social. La búsqueda por la producción se limitó a las Revistas de Psicología (en interfaz con lo social), indexadas en la Red Scielo y en la LILACS - Biblioteca Virtual en Salud (Bireme). Se han encontrado sólo dos artículos, lo que apunta a una fragilidad de las investigaciones en este campo, lo que solicita a la Psicología Social una reflexión sobre tal resultado, una vez que restringe su participación en los movimientos y luchas por la equidad étnico-raciales en Brasil.

Palabras clave: Psicología social. Equidad en salud. Religiones afrobrasileñas.

\section{Como citar o artigo:}

LAGES, S. R. C. SILVA, A. M. RIBEIRO, M. F. F. A participação das comunidades tradicionais de terreiro no campo da saúde: as pesquisas em psicologia social. Revista de Ciências Humanas, Florianópolis, v. 53, 2019 DOI 10.5007/2178-4582.2019.e42714.

\section{INTRODUÇAO}

No Brasil, historicamente, a população negra sofre uma série de desvantagens sejam elas econômicas, sociais ou simbólico-culturais. Um olhar atento a essas desigualdades a encontrará nas estatísticas com o maior número de desemprego, com os piores postos de trabalho, as piores condições de vida, de educação, moradia, com menor mobilidade social, dentre outros. Essa realidade é decorrente da ideologia racista presente na sociedade brasileira que opera através de marcadores raciais apoiados em fenótipos (cor da pele, tipo de cabelo, etc) de determinados indivíduos e coletivos, distribuindo privilégios a partir deles e também os hierarquizando. Aliados a essa perspectiva simbólico-cultural, reforçam os preconceitos e a discriminação racial, os fatores estruturais, históricos e de classe social.

Diante desse cenário, segundo Maio e Monteiro (2005),

raça emerge não apenas como uma ferramenta analítica para tornar inteligíveis os mecanismos estruturais das desigualdades sociais, mas também como instrumento político para a superação das iniquidades históricas existentes no Brasil. (MAIO: MONTEIRO, 2005, p. 420).

Neste mesmo sentido, Guimarães (1999) fala da importância do termo raça para a construção da identidade negra, é somente assumindo a "percepção racializada de si mesmo e do outro", apontando os privilérgios que os brancos possuem na sociedade brasileira, é que será possível enxergar a si mesmo como sendo oprimido e marginalizado por causa da sua cor. Daí a importância do recorte racial nas diferentes esferas de participação social, como no caso da saúde e da educação, uma vez que ele orienta as políticas públicas para as ações afirmativas no país.

Mas foi bem recentemente, a partir da Constituição de 1988, que essa situação começou a se modificar de forma mais proeminente, momento esse que a prática do racismo se tornou um crime 
inafiançável e imprescritível, o que abriu caminho para o reconhecimento dessas desigualdades e pela afirmação da identidade negra.

No que nos interessa aqui mais de perto, as relações entre raça e saúde abarcaram uma série de debates e iniciativas que acabaram por constituir um campo de reflexão e política denominado Saúde da população Negra, como dispositivo para o enfrentamento do racismo no país, e emergindo o termo raça “ [...] não apenas como uma ferramenta analítica para tornar inteligíveis os mecanismos estruturais das desigualdades sociais, mas também como instrumento político para a superação das iniquidades históricas existentes no Brasil.” (MAIO; MONTEIRO, 2005, p. 420).

O esforço por parte de técnicos do Ministério da Saúde, da sociedade civil, dos movimentos sociais, pesquisadores e militantes, acabou por fazer concretizar em 1996 um documento sobre o tema que destacou as principais linhas de atuação no campo da Saúde da População Negra: (a) os das doenças geneticamente determinadas (anemia falciforme, hipertensão arterial, o diabete mellitus e uma forma de deficiência de enzima hepática, a glicose-6-fosfato desidrogenase ); (b) as doenças vinculadas às condições sócio-econômicas, educacionais e psíquicas (alcoolismo, toxicomania, desnutrição, mortalidade infantil elevada, abortos sépticos, anemia ferropriva, Doença Sexualmente Transmissível (DST)/ Acquired Immunodeficiency Syndrome (AIDS), doenças do trabalho e transtornos mentais); (c) os males da saúde derivado da combinação de determinantes genéticos com desfavoráveis condições sociais de vida, até mesmo no plano cultural, a saber (hipertensão arterial, diabete mellitus, coronariopatias, insuficiência renal crônica, cânceres e miomas); e (d) as doenças associadas aos determinantes fisiológicos que, acrescidos das precárias condições de vida, transformam processos aparentemente naturais (crescimento, gravidez, parto e envelhecimento) em graves problemas sociais. (Ibid. p.425).

Alguns dados do Instituto de Pesquisa Econômica Aplicada (IPEA) (2011), ilustram a situação da saúde da população negra. No que se refere à Atenção Integral à Saúde da Mulher, constatou-se que enquanto $5,1 \%$ das mulheres brancas não receberam anestesia no parto normal, esse percentual dobrou, no caso das mulheres negras, 11,1\%. Com dependência total do Sus, as mulheres pretas, pardas, tiveram pior atenção no pré-natal, não sendo aceitas na primeira maternidade que procuraram e recebendo menos anestesia. Nos serviços de alta complexidade, as disparidades também são enormes, como no caso de transplantes, quando o acesso a esse sistema, considerando pretos e pardos é muito menor que o das pessoas brancas. (IPEA). Outros dados sobre a desigualdade em saúde no Brasil podem ser vistos em Paixão (2010).

Cabe destacar um outro momento de fundamental importância para as lutas em prol da equidade em saúde no Brasil, que foi a $3^{\text {a }}$ Conferência Mundial de Combate ao Racismo, Discriminação Racial, Xenofobia e Intolerância Correlata, realizada em Durban, África do Sul, em 2001 que se desdobrou no documento Política Nacional de Saúde da População Negra. (PNUD; 
OPAS, 2001). A partir de então, um conjunto de ações foram implementadas, decorrentes das políticas públicas voltadas para a saúde da mulher negra, para o controle e combate da anemia falciforme, e implementados estudos quanto à vulnerabilidade do HIV/Aids da população negra.

Diante desse quadro, da complexidade e da extensão da problemática estabelecida pelo campo da Saúde da População Negra, outros territórios fossem considerados como sendo de promotores de saúde e importantes para a prevenção das doenças que atingem de forma mais específica aqueles grupos, os das religiosidades afro-brasileiras. Essa consideração está registrada em documentos do Ministério da Saúde (2007) que reconhecem aqueles espaços religiosos como promotores de educação em saúde. (LAGES, 2010).

No entanto, apesar da presença histórica do campo religioso afro-brasileiro no país, de sua ligação com a saúde e com grande parte da população negra, ela continua sendo alvo de preconceitos e discriminação, tanto por parte das igrejas cristãs como de muitos grupos sociais, que a demonizam e/ou a vêm com um sentido primitivo. Por outro lado, pesquisadores têm demonstrado a forte participação das religiões afro-brasileiras em suas diferentes denominações (candomblé, umbanda, pajelança, tambor de mina, batuque, dentre outras), com a saúde e a medicina fitoterápica. (SILVA, 2007; LAGES, 2010; 2012; FERRETTI, 2008; MELLO, 2013).

Considerando esse contexto, apresentamos parte de uma pesquisa interface com a extensão, que foi realizada de 2012 a 2014, e que teve como foco a iniquidade no campo da saúde da população negra e a luta das comunidades tradicionais de terreiro pelo reconhecimento de seus saberes e fazeres sobre a saúde, reconhecimento este inscrito no Programa da Saúde da População Negra do governo federal. Relatamos aqui os resultados da pesquisa no que concerne à revisão bibliográfica considerando as pesquisas em psicologia social a partir do recorte saúde e religiões de matriz africana.

\section{MÉTODO}

Foi utilizado o da revisão bibliográfica, apropriado para contribuir com a construção de um campo teórico de determinada área do conhecimento, apontando os temas mais estudados, as lacunas na pesquisa, indicando possibilidades de futuras pesquisas, e facilitando o trabalho dos pesquisadores interessados no tema. (ENS; ROMANOWSKI, 2006).

Esclarecemos que essa revisão bibliográfica possui caráter exploratório, o que pressupõe futuras pesquisas que possam ampliar e aprofundar a realidade investigada.

O levantamento limitou-se às revistas de Psicologia Social, indexadas na Rede Scielo, Brasil, a partir de 1997, início de sua coleção, e na LILACS - Biblioteca Virtual em Saúde (Bireme), estabelecido no Brasil desde 1967. 
No entanto, as poucas produções encontradas no campo da Psicologia Social, fez com que o leque da investigação fosse ampliado na tentativa de localizar outros estudos com afinidade temática. Esses artigos serão aqui relacionados.

Informamos que para selecionar as revistas de Psicologia Social, foi estabelecido o critério de destacar aquelas que dialogam com a sociedade num sentido crítico, que estejam comprometidas com as transformações sociais, que tenham por objetivo desconstruir as naturalizações que estigmatizam e oprimem determinados coletivos, seja com relação às questões étnicas-raciais, de gênero, de orientação sexual, geracional, dentre outros. Para tanto, foi lido foco e escopo das referidas revistas.

O levantamento utilizou um rol de palavras-chaves para o processo de localização dos textos, para em seguida, proceder a leitura dos resumos, identificando o tema e a metodologia utilizada. As palavras-chaves foram: umbanda; preto-velho; saúde pública; tradução cultural; religiões afrobrasileiras; saúde da população negra; controle social; práticas terapêuticas; saúde; cuidado; candomblé; políticas públicas; população negra; intolerância religiosa; práticas terapêuticas; sincretismo; cura místico-religiosa; subjetividade; psicoterapia; saúde mental coletiva; misticismo; grupo com ancestrais do continente africano; integralidade; religião de matriz afro-brasileira; equidade em saúde; saúde e doença; antropologia da saúde; etnografia; promoção da saúde. E os descritores: religião e psicologia; atenção primária à saúde; conhecimentos, atitudes e prática em saúde; pesquisa qualitativa; comunidade tradicional de Terreiro; terapias espirituais.

\section{APRESENTAÇÃO E ANÁLISE DE RESULTADOS}

O levantamento bibliográfico nas fontes pesquisadas apontou trabalhos em outras áreas do conhecimento, conforme acima colocado, e juntamente com os da Psicologia Social, totalizaram 11 artigos.

Desse conjunto, podem-se eleger os seguintes eixos de pesquisa: 03 abordaram a relação das políticas públicas para a saúde da população negra com as religiosidades afro-brasileiras, e as formas de cooperação possíveis entre essas diferentes instâncias (SILVA, 2007; SERRA; PECHINE; PECHINE,2010; GOMES, 2010); 03 enfatizaram questões sobre a sexualidade e os procedimentos terapêuticos realizados nos terreiros para o tratamento da Aids, trazendo também a discussão com a saúde pública (SILVA et al, 2008; RIOS et al. 2013; SOUZA et al, 2014); e 05 versaram sobre a concepção de saúde-doença, do sofrimento psíquico, e as formas de tratamento (COSTA-ROSA, 2008; ALVES; SEMINOTTO, 2009; MOTTA; TRAD, 2011; MELLO, 2013; OLIVEIRA, 2013; LAGES, 2012). 
Especificamente quanto às publicações da Psicologia Social, destacam-se: o de Silva et al (2008) - Revista Psicologia em Estudo e de Lages (2012) - Psicologia Argumento. Ainda no campo da psicologia, mas numa vertente fronteiriça das ciências humanas e biológicas, encontra-se o trabalho de Costa-Rosa (2008) - Revista Psicologia-USP.

É importante observar, considerando as bases de dados investigadas, que é a partir de 2007 que as publicações aparecem, e provavelmente consequência da III Conferência Mundial de Combate ao Racismo, Discriminação Racial, Xenofobia e Intolerância Correlata, em Durban (África, agosto/2001), e de uma série de movimentos que se articularam (movimento social negro, sociedade civil organizada, organismos internacionais, docentes de universidades, alguns setores do Estado), que acabou por culminar na Política Nacional para a Saúde da População Negra: uma questão de equidade, em dezembro/2001.

No que diz respeito aos periódicos, e considerando as áreas acima, observa-se que o periódico com maior número de publicações relacionadas ao assunto é a revista Saúde e Sociedade, com três artigos publicados (28\%) nos anos de 2007, 2011e 2013; seguida pela revista Ciência e Saúde Coletiva com duas publicações (18\%) nos anos de 2013 e 2014. O restante dos periódicos encontrados obteve uma publicação (9\%).

Outros estudos também contribuem com a investigação sobre a temática. O livro organizado por Mandarino; Gomberg (2009), Leituras afro-brasileiras: territórios, religiosidades e saúde, é uma coletânea de 18 capítulos que reúne textos de diversos autores nas áreas de Saúde Coletiva e Ciências Sociais, dos quais 10 capítulos tratam de temas estreitamente ligados aos que são foco do levantamento bibliográfico que foi realizado. O objetivo dessa obra foi trazer reflexões acerca das populações afro-brasileiras reunindo ideias e percepções de agentes religiosos de diversas instituições, bem como demonstrar os resultados de pesquisas a respeito de assuntos relacionados a religiosidades afro-brasileiras.

E, ainda, a tese de doutorado de Mello (2013), Práticas terapêuticas populares e religiosidade afro-brasileira em terreiros no Rio de Janeiro: um diálogo possível entre saúde e antropologia.

$\mathrm{Na}$ área da Psicologia, Costa-Rosa (2008), apresenta Práticas de cura místico-religiosas, psicoterapia e subjetividade contemporânea. Este trabalho foge ao propósito deste artigo, uma vez que se fundamenta em conceitos e metodologias alijadas da psicologia crítica social. Mas consideramos pertinente apresentá-lo até mesmo para evidenciar as diferentes maneiras que o recorte da saúde, no fenômeno religioso, pode ser interpretado pela psicologia. De uma forma simplificada, o autor tem o objetivo de investigar a eficácia terapêutica (ou não) nas práticas de cura oferecidas pelo que ele chama de instituições místico-religiosas, comparando-as com o serviço ambulatorial de tratamento de saúde mental na rede pública. De forma específica ele se interessa em saber o grau de eficácia (ou não) das práticas de cura entre as diferentes igrejas; em que circunstância o saber da 
medicina falhou; quais as fronteiras entre o patológico e doenças espirituais; qual o papel da consonância cognitiva no compartilhamento de crenças; qual o efeito da cura na subjetividade dos indivíduos; e se poderia estabelecer uma relação entre a situação terapêutica das práticas de cura e a psicoterapia psicanalítica.

Ficou difícil apresentar aqui as análises que são feitas sobre a Umbanda, devido à metodologia adotada pelo autor, que deixou em muitos pontos o texto confuso. De forma geral, para o autor a maioria dos indivíduos que procuram as referidas práticas de cura na Umbanda se queixam de transtornos psíquico-somáticos e buscam um saber sob a forma de revelação mística, estão engajados na religião pela fé.

Quanto aos artigos da Psicologia Social, Silva et al (2008), em Religiosidade, juventude e sexualidade: entre a autonomia e a rigidez, faz uma descrição da visão de jovens e lideranças religiosas sobre a sexualidade visando contribuir com as políticas públicas de promoção da saúde sexual. O estudo foi realizado na região metropolitana da cidade de São Paulo, nas religiões: católica, umbanda, candomblé e diversas denominações evangélicas. Os temas investigados foram: iniciação sexual, casamento, gravidez, métodos de prevenção das DST's/AIDS, homossexualidade, aborto e direitos humanos; e para tanto, utilizou a entrevista semi-estruturada.

Com referência à Umbanda e Candomblé, os autores apontam que nos relatos, o sexo foi colocado como um presente dos orixás e que o período de iniciação sexual está de acordo com a maturidade de cada pessoa, no entanto, não ficam claros quais são os requisitos para essa maturidade. Em relação a diversidade e direitos sexuais os umbandistas demonstraram abertura e flexibilidade para considerar os preceitos das diversas religiões, respeitando as opiniões diferentes e até mesmo contrárias as suas, em comparação com as demais religiões.

Em relação à homossexualidade, para os jovens do candomblé o assunto foi tratado como natural, alguns jovens inclusive relataram experiências homoafetivas e a conduta foi considerada aceita pela comunidade religiosa. Já a gravidez não planejada foi citada de maneira espontânea, nesse caso sendo considerada um erro e irresponsabilidade em não usar os métodos contraceptivos, assim como o aborto, que é visto como uma interrupção no curso natural da vida e um atraso nas leis de reencarnação espiritual gerando graves consequências. Os jovens da Umbanda e Candomblé demonstraram maior informação e conhecimento dos métodos contraceptivos e prevenção de DST's/AIDS. Nesse sentido, colocam os autores sobre a importância das lideranças religiosas para a educação em direitos sexuais, reprodutivos, e preventivos para os jovens, articulado com a superação do preconceito contra a referida religiosidade.

Os estudos, já acima referenciados (de outras áreas do conhecimento), de Rios, et al (2013), Axé, práticas corporais e Aids nas religiões africanistas do Recife, Brasil; e de Souza, et al (2014) Itinerários terapêuticos de travestis da região central do Rio Grande do Sul, Brasil, também apontam 
elementos que reforçam a perspectiva de Silva at al (2008): o da importância dos terreiros, principalmente para os adeptos jovens, como espaço de informação, educação e prevenção do DST/AIDS, articulando o axé, categoria da religiosidade candomblecista utilizada para se pensar os sujeitos em todas as suas dimensões, e influenciá-las, de forma a torná-los mais saudáveis e dispostos para a vida; o acolhimento diferenciado do terreiro que respeita a opção homossexual dos sujeitos, sem julgamento moral.

Já o trabalho de Lages (2012), Saúde da população negra: a religiosidade afro-brasileira e a saúde pública, busca, apoiada no conceito de epistemicídio e tradução cultural de Santos (2008), estudar as possibilidade de diálogo entre os saberes da medicina hegemônica e os das comunidades de terreiro umbandistas. Com esse objetivo as narrativas dos sujeitos entrevistados foram analisadas na busca por elementos viabilizadores para uma troca de saberes. Tal possibilidade parte da necessidade de ampliar e potencializar outros espaços de saúde diante das desigualdades no campo da saúde da população negra e do racismo institucional na saúde pública. O referido diálogo, segundo a autora, poderia potencializar a maior participação desses coletivos no controle social da saúde pública.

Para tanto, considera que as referidas comunidades são espaços de informação e educação em saúde, e analisa os documentos em que estão registrados tais possibilidades: os do Ministério da saúde, das Políticas Nacionais de Humanização do SUS; das estratégias da Organização Mundial de Saúde (OMS) sobre medicina Tradicional, e o documento Estratégia de Municípios e Comunidades Saudáveis da OMS. Como recurso metodológico utilizou de entrevistas semi-estruturadas com lideranças de terreiros da Umbanda, e da análise de discurso para interpretação das narrativas.

Argumenta a autora que os saberes e práticas da religiosidade umbandista, desenvolvida nos chamados terreiros, e no mesmo sentido que Alves e Seminotti (2009), concebem o ser humano a partir de uma perspectiva que integraliza corpo, mente e espiritualidade. Chama atenção, ainda, para outras dimensões, a social e a cultural, que de acordo com os sujeitos entrevistados são causadores de doenças, ou seja, a pobreza, o desemprego, o preconceito e a discriminação, desestabilizam as pessoas causando uma série de doenças psíquico-somáticas. E acrescenta também, que os procedimentos terapêuticos utilizados, aliam o uso dos chás e das ervas ao acolhimento e aconselhamentos, baseados numa escuta atenciosa dos sofrimentos físicos e psíquicos relatados pelos sujeitos afiliados a este sistema de crença, o que é preconizado pelo HumanizaSus. A saúde-doença, pois, seria uma relação tecida por complexidades oriundas de diferentes esferas das experiências dos sujeitos. É justo essa concepção de saúde e de doença, que também está presente dos documentos acima citados.

São estes pontos de contato, entre esferas tão diferentes dos saberes, que possibilitariam o diálogo entre a saúde pública e as comunidades tradicionais de terreiro. O diálogo pressupõe o 
respeito pelas diferenças culturais e o reconhecimento da importância que as comunidades tradicionais de terreiro têm tido, historicamente, para determinados coletivos.

Para Lages (2012), a tradução cultural é possível, uma vez que as lideranças entrevistadas afirmaram a incompletude dos saberes e fazeres da referida comunidade de terreiro para o tratamento das doenças, considerando os procedimentos realizados como complementares à medicina oficial. Os documentos analisados também apontam a incompletude do saber médico, solicitando a valorização dos territórios tradicionais.

A investigação da autora se alinha àquelas dos autores supracitados, Alves e Seminotti (2009), em compreender a concepção de saúde e a origem do sofrimento psíquico por adeptos de uma comunidade tradicional de terreiro; Mota e Bomfim Trad (2011), A gente vive para cuidar da população: estratégias de cuidado sentidos para a saúde, doença e cura nos terreiros de candomblé; e Mello e Oliveira (2013), em Saúde, religião e cultura: um diálogo a partir das práticas afro-brasileiras.

Esse alinhamento diz respeito a alguns pontos de convergência com relação à saúde-doença e os saberes e fazeres das comunidades tradicionais de terreiro como: a concepção integral dos sujeitos em suas diferentes dimensões (corpo, mente, espiritualidade); o uso da medicina fitoterápica, chás e ervas, aliado ao acolhimento e orientações que são oferecidos nos terreiros por suas entidades espirituais; a importância das comunidades tradicionais de terreiro para o reconhecimento da identidade afro-brasileira; a postura inclusiva dessas comunidades para receber a diversidade cultural e de diferentes orientações sexuais, são elementos que contribuem com a medicina preventiva. Essa contribuição abre as possibilidades de construção de uma zona de contato, no sentido boaventuriano, onde as trocas de saberes poderiam se tornar uma realidade, conforme Lages (2012) argumenta.

\section{CONSIDERAÇÕES FINAIS}

A fragilidade das publicações no campo da Psicologia Social crítica, com referência ao tema, demonstra a necessidade de um maior investimento na investigação e aprofundamento do papel que as comunidades tradicionais de terreiro possuem para com a saúde da população negra, e também para com a promoção da visibilidade e do reconhecimento das contribuições dessas expressões para com a cultura brasileira. Mas apesar das poucas publicações, elas acabaram reforçando estudos de outras áreas do saber, que na contramão dos preconceitos étnico-raciais, reposicionam as comunidades tradicionais de terreiro, tanto como centros de resistência cultural, como espaços promotores de saúde, como foi demonstrado.

É importante aqui registrar, que no sentido acima colocado, a Rede Nacional de Religiões Afro-brasileiras e Saúde desde 2003, vem construindo parecerias com o SUS - Sistema Único de Saúde, através de ações que envolvem a luta pelo direito humano à saúde; a valorização e 
potencialização do saber dos terreiros em relação à saúde; o monitoramento e intervenção nas políticas públicas de saúde, exercendo o controle social; no combate ao racismo, sexismo, homofobia, lesbofobia e todas as formas de intolerâncias. Essa experiência está relatada no trabalho já citado de Silva (2007). (Rede Nacional de Religiões Afro-brasileiras e Saúde).

Cabe à Psicologia Social, em sua vertente da crítica social, ampliar as investigações sobre a relação das comunidades tradicionais de terreiro com a saúde, podendo assim contribuir com os processos emancipatórios de um coletivo que vem ao longo da história brasileira lutando pelo reconhecimento de suas identidades, de suas expressões culturais e dos seus saberes e práticas com referência à saúde.

\section{REFERÊNCIAS}

ALVES, Miriam Cristiane.; SEMINOTTI, N. Atenção à saúde em uma comunidade tradicional de terreiro. Revista de Saúde Pública, São Paulo, 2009, v. 43, supl. 1,p. 85-91. Disponível em: http://www.scielo.br/scielo.php?script=sci_arttext\&pid=S0034$89102009000800013 \& \operatorname{lng}=$ pt\&nrm=iso. Acesso em 27 out 2015.

BRASIL. Declaração de Durban e Plano de Ação - III Conferência Mundial de Combate ao Racismo, Discriminação Racial, Xenofobia e Intolerância Correlata. Ministério da Cultura. São Paulo: Fundação Palmares, 2005.

BRASIL. Política Nacional de Saúde Integral da População negra. Brasília: Secretaria de Gestão Estratégica e Participativa. Ministério da Saúde, 2007.

COSTA ROSA, Abílio. Práticas de cura místico-religiosas, psicoterapia e subjetividade contemporânea. Psicologia USP, São Paulo, 2008, v. 19,n. 4,p. 561-590. Disponível em: http://www.scielo.br/scielo.php?script=sci_arttext\&pid=S010365642008000400012\&lng=en\&nrm=iso. Acesso 20 ago 2014.

ENS, Romilda Teodora; ROMANOWSKI, Joana Paulim. As pesquisas denominadas do tipo “estado da arte” em educação. (Vol. 6) Curitiba: Diálogo Educacional, 2006, 19, p. 37-50.

FERRETTI, M. Cura e pajelança em terreiros do Maranhão (Brasil). I Quaderni del CREAM, Milano, v. 8, p. 67-91, 2008.

GOMES, Márcia C. Pinto Aderne. Projeto: Ylê ayié yaya ilera (Saúde plena na casa desta existência): equidade e integralidade em saúde para a comunidade religiosa afro-brasileira.

Interface, 2010, 34, vol. 14. Disponível em:

http://www.scielo.br/scielo.php?script=sci_arttext\&pid=S1414-

$32832010000300015 \& \operatorname{lng}=$ en\&nrm=iso. Acesso em 20 agosto 2014.

INSTITUTO DE PESQUISA ECONÔMICA APLICADA - IPEA. Desigualdade racial no Brasil, um olhar sobre a saúde. Disponível em

http://www.ipea.gov.br/desafios/index.php?option=com_content\&view=article\&id=2688:catid=28

\&Itemid=23. Acesso em 20 outubro 2016. 
LAGES, S.R. C. Os terreiros de Umbanda e a promoção da saúde da população negra. In: PEREIRA, E. A.; DAIBERT JÚNIOR, R. (Org.). Depois, o Atlântico - modos e pensar, crer e narrar na diáspora africana. 1ed.Juiz de Fora: UFJF, 2010, v. 1, p. 185-200.

LAGES, Sônia Regina Corrêa. Saúde da população negra: A religiosidade afro-brasileira e a saúde pública. Psicologia Argumento, 2012, n. 69. Disponível em:

http://www2.pucpr.br/reol/index.php/PA?dd1=5986\&dd99=view. Acesso em 20 ago 2014.

MAIO, Marcos Chor; MONTEIRO, Simone. Tempos de racialização: o caso da 'saúde da população negra' no Brasil. Hist. cienc. saude-Manguinhos, Rio de Janeiro, v. 12, n. 2, p. 419-446, Aug. 2005 . Available from $<\mathrm{http}: / / w w w . s c i e l o . b r / s c i e l o . p h p ?$ script $=$ sci_arttext\&pid=S0104$59702005000200010 \& \operatorname{lng}=\mathrm{en} \& \mathrm{nrm}=\mathrm{iso}>$. access on 13 May 2019. http://dx.doi.org/10.1590/S0104-59702005000200010.

MANDARINO, Ana Cristina Souza; GOMBERG, Estélio.(org.) Leituras afro-brasileiras: territórios, religiosidades e saúde. Salvador: Editora UFS; EDUFBA, 2009. Disponível em: https://repositorio.ufba.br/ri/bitstream/ufba/194/1/Leituras\%20afro-brasileiras.pdf. Acesso em 20 setembro de 2014.

MELLO, Márcio Luíz; OLIVEIRA, Simone Santos. Saúde, Religião e Cultura: um diálogo a partir das práticas afro-brasileiras. São Paulo: Revista Sociedade, 2013, vol. 22, 4. p. 1024-1035. Disponível em: http://www.scielo.br/pdf/sausoc/v22n4/06.pdf. Acesso em 05 outubro 2014.

MELLO, Márcio Luíz. Práticas terapêuticas populares e religiosidade afro-brasileira em terreiros no Rio de Janeiro: um diálogo possível entre saúde e antropologia. Tese (Doutorado em Ciências na área de Saúde Pública). Escola Nacional de Saúde Pública Sergio Arouca, 2013. Disponível em: http://bases.bireme.br/cgi-bin/wxislind.exe/iah/online/. Acesso em 20 agosto 2014.

MOTA, Clarice Santos; TRAD, Leny Alves Bonfim. A gente vive pra cuidar da população: estratégias de cuidado e sentidos para a saúde, doença e cura em terreiros de candomblé. (Vol. 20). São Paulo: Saúde e Sociedade, 2011, vol. 20. Disponível em: http://www.scielo.br/scielo.php?script=sci_arttext\&pid=S0104$12902011000200006 \& \operatorname{lng}=$ en\&nrm=iso. Acesso em 20 agosto de 2014.

PAIXÃO, Marcelo e outros. Relatório Anual das desigualdades raciais no Brasil. 2009-2010. Disponível em: http:/www.palmares.gov.br/wpcontent/uploads/2011/09/desigualdades_raciais_2009-2010.pdf. Acesso em 14 setembro 2015.

RIOS, Luiz Felipe et al. Axé, práticas corporais e Aids nas religiões africanistas do Recife. Ciência e saúde coletiva, 2013, vol. 18, 2. Disponível em: http://www.scielosp.org/scielo.php?script=sci_arttext\&pid=S1413$81232013002000021 \& \operatorname{lng}=\mathrm{en} \& n r m=$ is. Acesso em 20 setembro 2014.

SERRA, Ordep; PECHINE, Maria C. Santos; PECHINE, Serjio. Candomblé e políticas públicas de saúde em Salvador. Mediações - Revista de Ciências Sociais, 2010, vol. 15, 1. Disponível em: http://www.uel.br/revistas/uel/index.php/mediacoes/issue/view/534http://www.uel.br/revistas/uel/in dex.php/mediacoes/article/view/6547/5953. Acesso em 20 agosto 2014.

SILVA, Cristiane Gonçalves et al. Religiosidade, juventude e sexualidade: entre a autonomia e a rigidez. Psicologia em Estudo, 2008, vol. 13, 4. Disponível em: http://www.scielo.br/scielo.php?script=sci_arttext\&pid=S1413$73722008000400006 \& \operatorname{lng}=$ pt\&nrm=iso. Acesso em 20 setembro 2014. 
SILVA, José Marmo. Religiões e saúde: a experiência da Rede Nacional de Religiões AfroBrasileiras e Saúde. Saúde e Sociedade, 2007, vol. 16, 2. Disponível em:

http://www.scielo.br/scielo.php?script=sci_arttext\&pid=S0104-

$12902007000200017 \& \operatorname{lng}=$ en\&nrm=iso. Acesso em 20 agosto 2014.

SOUZA, Martha Helena Teixeira et al. Itinerários terapêuticos de travestis da região central do Rio Grande do Sul, Brasil. Ciência e saúde coletiva, 2014, vol. 19, 7. Disponível em:

http://www.scielosp.org/scielo.php?script=sci_arttext\&pid=S1413-

$81232014000702277 \& \operatorname{lng}=$ en\&nrm=iso. Acesso em 20 setembro de 2014.

Submetido em: 22-1-2016

Histórico Recebido em: 31-10-2017

Aceito em: 26-2-2018

FAPEMIG (informar o tipo de fomento e o número do processo através do qual foi concedido): Tipo Agência de fomento: de fomento: Edital 07/12 - Apoio a projetos de extensão em interface com a pesquisa - compra de equipamentos e bolsa para alunos (Processo no. : SHA - APQ-02751-12) 